\title{
PRAGMATISMO E LINGUAGEM: FUNDAMENTOS DE UM PRAGMATISMO LINGUÍSTICO SEGUNDO O PENSAMENTO DE PEIRCE, JAMES E DEWEY ${ }^{1}$
}

\author{
JORGE FRANCISCO DA SILVA ${ }^{2}$ \\ KARL KEINZ EFKEN ${ }^{3}$
}

\author{
Programa de Pós-graduação em Ciências da Linguagem \\ Universidade Católica de Pernambuco \\ Rua do Príncipe, 526 - Boa Vista, Recife - PE, 50050-900 \\ jestradutorpublico@gmail.com , khefken@hotmail.com
}

\begin{abstract}
Resumo. Apesar da centralidade da questão da significação na linguagem, o número de trabalhos com foco em estudos pragmáticos é bem inferior em comparação com pesquisas em outros núcleos duros da linguística. Assim, o objetivo deste artigo é resgatar o pensamento original dos pragmáticos clássicos norte-americanos (Peirce, James e Dewey) e identificar fundamentos teóricos para desenvolver uma proposta de pragmatismo linguístico. A semiótica de Peirce, juntamente com os conceitos de 'cash value' em James e 'warranted assertibility' (discursos justificáveis) em Dewey são apresentados como instrumentos para a análise do papel das crenças, hábitos e ações na construção dos sentidos na linguagem.
\end{abstract}

Palavras-chave: Semiótica; cash value; warranted assertibility; pragmatismo linguístico.

\begin{abstract}
Despite the centrality of the question of signification in language, the number of studies focusing on pragmatic studies is much lower compared to research in other hardcore areas in linguistics. Thus, the purpose of this article is to revisit the original works of the American pragmatists (Peirce, James and Dewey) in order to identify theoretical principles to develop a proposal of linguistic pragmatism. Peirce's semiotics, together with the concepts of 'cash value' in James and 'warranted assertibility' in Dewey are presented as tools for analyzing the role of beliefs, habits and actions in the construction of meaning in language.
\end{abstract}

Keywords: Semiotics; cash value; warranted assertibility; linguistic pragmatism.

\footnotetext{
${ }^{1}$ Trabalho apresentado como comunicação durante o $17^{\circ}$ Encontro Internacional sobre Pragmatismo da Pontifícia Universidade Católica de São Paulo entre 06 - 09 de novembro de 2017. Disponível em $<$ https://www.pucsp.br/pragmatismo/encontros intern pragmatismo/17 encontro internacional.html $>$

2 Doutorando no Programa de Pós-graduação em Ciências da Linguagem da Universidade Católica de Pernambuco.

${ }^{3}$ Docente e pesquisador no Programa de Pós-graduação em Ciências da Linguagem da Universidade Católica de Pernambuco.
} 


\title{
CONSIDERAÇÕES INICIAIS
}

\begin{abstract}
Somos uma espécie muito estranha e a nossa capacidade de linguagem parece estar na raiz do problema [...] com 25 ou 30 sons, sem relação com nada em nossas mentes, somos de alguma forma capazes de produzir um número infinito de pensamentos que expressam qualquer coisa que possamos imaginar ou 'os movimentos de nossa alma', qualquer coisa que esteja acontecendo em nossa vida mental. (CHOMSKY, 2016, tradução nossa) ${ }^{4}$
\end{abstract}

Este artigo faz parte de um projeto de pesquisa em aperfeiçoamento sobre pragmatismo linguístico ${ }^{5}$ e suas competências. Existe hoje literatura suficiente para dar conta das competências comunicativas, com exceção das competências pragmáticas que padecem do fato de dependerem de uma área ainda em desenvolvimento dentro dos campos de interesse das ciências da linguagem - os estudos pragmáticos.

Assim, o objeto de estudo deste artigo é a pragmática definida como: "disciplina que analisa o uso concreto da linguagem feito pelos seus usuários e as condições que governam essa prática" (HABERLAND; MEY, 1977, p. 1). E a primeira pergunta que surge é sobre o estado atual das pesquisas sobre pragmatismo linguístico no Brasil e no mundo.

Segundo Rajagopalan (1999), além das condições sabidamente precárias da pesquisa no Brasil, a própria indefinição a respeito do que vem a ser pragmatismo linguístico age como fator complicador que compromete o avanço dos estudos pragmáticos. E tal indefinição atinge pesquisadores no mundo inteiro.

Rajagopalan admite que "a pragmática ainda é vista por muitos estudiosos, não sem razão, como um verdadeiro saco de gatos" (1999, p. 323). E prossegue: "o interesse da pragmática, para mim, sempre foi a inexistência da disciplina propriamente dita - na verdade, parece muito mais sensato falar em pragmáticas, no plural” (Idem).

Rajagopalan (1999) cita ainda um desabafo de Marcuschi durante a $48^{\mathrm{a}}$ Reunião Anual da SBPC realizada em São Paulo, em 1996. Durante o seu pronunciamento, Marcuschi lamentou o quadro confuso que encontrou quando se propôs fazer um levantamento sobre o interesse dos pesquisadores nas diferentes subáreas da Linguística:

É possível que eu não seja a pessoa mais indicada para classificar essa massa de dados. Há muita coisa que imaginei ser da área de Teoria Literária, Teoria da Cultura ou outras Teorias. Posso honestamente garantir que me esforcei para não falsear a visão dos fatos. Confesso também que as caracterizações [como elas se encontram feitas] não me

\footnotetext{
${ }^{4}$ Chomsky citando Galileu, citando Aristóteles. O texto da epígrafe é conhecido como 'o desafio de Galileu'. (Os autores)

${ }^{5}$ Optamos por usar onde possível a expressão pragmatismo linguístico em lugar de pragmática para evitar possíveis confusões com pragmatismo como corrente de pensamento filosófico. Entretanto, alguns autores preferem usar o termo mais tradicional e tal uso será respeitado. (Os autores)
} 
agradam, pois elas mascaram os fatos. Há mais trabalhos de sintaxe e fonologia do que se imagina, mas eles são autocaracterizados como linguística indígena (descrição fonológica, sintática) ou psicolinguística (aquisição da sintaxe, da fonologia). Não há nada que se caracterize ou que se identifique de maneira explícita com semântica ou pragmática. Mas muitos dos trabalhos estão impregnados de semântica e pragmática. Não, porém, de uma forma mais técnica e teoricamente centrada. [...] a mesma indefinição pode ser encontrada nos resumos dos seminários da ANPOLL, dos congressos da ABRALIN, e nas programações e nos Anais do GEL. (MARCUSCHI, 1996, p. 21-22, grifo nosso).

O diagnóstico, sem filtros, de Rajagopalan sobre o estado da arte do pragmatismo linguístico tem o mérito de ser ao mesmo tempo revelador e desencorajador. Se, por um lado, é possível tomar pé da situação com base na avaliação de trabalhos dos pesquisadores mais importantes da área, por outro lado, somos confrontados com sua própria história de insucessos devido a fatores como a falta de definições e a complexidade dos temas envolvidos.

Entretanto, em resposta aos desafios por ele mesmo apontados, Rajagopalan adota uma postura realista em um de seus comentários acima e confessa que seu interesse sobre as questões referentes ao pragmatismo linguístico repousa sobre a possibilidade de se pensar em 'disciplinas pragmáticas com diferentes orientações'.

Pinto (2012), à semelhança de seu orientador Rajagopalan, procura traçar um panorama geral dos estudos pragmáticos no Brasil, com seus percalços, ambiguidades, controvérsias, mas também aponta alguns caminhos:

De que tratam os estudos linguísticos que se classificam como 'pragmáticos', ou pertencentes à área da Pragmática? Essa é uma pergunta que pode gerar respostas tão variadas quanto o número de pessoas que se dispuserem a respondê-la. Um número muito grande de trabalhos, com temas e objetivos mais diversos, circula nos periódicos e outras publicações declaradamente inseridos no domínio da Pragmática. Pode-se, no entanto, a partir de um grupo mais ou menos coeso, procurar delimitar a Pragmática, admitindo a diversidade. (PINTO, 2012, p. 55, grifo nosso).

Para Pinto (2012), os estudos pragmáticos definem e estudam a linguagem segundo os conceitos de sociedade e comunicação, descartados pela linguística saussureana em sua subtração da fala. A autora ressalta que os estudos pragmáticos são constituídos por três grupos principais:

1. O pragmatismo norte-americano, influenciado pelos estudos semiológicos (sic) de William James;

2. Os estudos dos atos de fala, influenciados pela filosofia da linguagem nos trabalhos de J. L. Austin;

3. Os estudos pragmáticos interdisciplinares com foco nas relações sociais, de classe, de gênero, raciais e culturais. 
As observações de Rajagopalan, Marcuschi e Pinto acima nos levam a concluir que os estudos pragmáticos necessitam de princípios e de um referencial teórico com maior poder de explicação sobre as condições que governam os usos da linguagem. E a segunda pergunta que este artigo procura responder é em que medida os diagnósticos, análises e observações acima podem contribuir para uma melhor fundamentação e caracterização de um pragmatismo linguístico.

Reiteramos a visão de Rajagopalan (1999) sobre a possibilidade de disciplinas pragmáticas com diferentes orientações e observamos que, da intersecção apontada por Pinto (2012) acima, partem três caminhos. O primeiro roteiro tem como destino a Virada Pragmática constituída a partir das contribuições do pensamento de Peirce, James e Dewey. O segundo trajeto conduz à Virada Linguística protagonizada, entre outros, por Frege, Austin e pelo segundo Wittgenstein. O terceiro caminho segue na direção da semântica discursiva inspirada pelos trabalhos do Círculo de Bakhtin.

As relações históricas e epistemológicas entre os dois primeiros caminhos certamente merecem ser exploradas oportunamente em futuros trabalhos de investigação. O segundo e o terceiro caminhos são os mais comumente usados pela disciplina pragmática e suas consequências, limitações e críticas já foram expostas e analisadas acima por Marcuschi (1996), Rajagopalan (1999) e Pinto (2012). Desse modo, nosso itinerário neste artigo prossegue por caminhos menos viajados em busca de princípios e conceitos para estruturar uma proposta de pragmatismo linguístico historicamente ligado à tradição pragmática, especialmente ao pensamento dos pragmáticos clássicos norteamericanos.

\section{ORIGENS DO PRAGMATISMO CLÁSSICO NORTE-AMERICANO}

Pragmáticos se afastam da abstração e da insuficiência, das soluções verbais, de raciocínios a priori pobres, dos princípios fixos, dos sistemas fechados e das pretensas origens e absolutos. Eles se voltam para a concretude e a adequação, para os fatos, para a ação e para o poder. (JAMES, 1907, p. 19, tradução nossa)

Bernstein (2010) credita William James (1842 - 1910), juntamente com John Dewey (1851 - 1952) e Charles Sanders Peirce (1839 - 1914), como os fundadores de um movimento filosófico norte-americano que floresceu durante os últimos trinta anos do século XIX e os primeiros vinte anos do século XX. Os pragmáticos clássicos norteamericanos acreditavam que o conhecimento só é significativo quando associado à ação. Nada é verdadeiro ou falso em si - apenas tem utilidade ou não. Essa filosofia estava profundamente enraizada nas realidades da vida, preocupada primeiramente com a experiência direta do indivíduo no mundo em que habitava.

Em essência, a aplicação prática do conhecimento era tudo. O movimento começou no início da década de 1870, em um clube de curta duração chamado The Metaphysical $C l u b^{6}$, em cujo âmbito ideias sobre várias questões começaram a tomar forma. A principal delas foi uma reação às ideologias filosóficas predominantes no século XIX, com seus excessos metafísicos e concepções muito abstratas sobre verdade e

${ }^{6}$ Cf. The Metaphysical Club, a story of ideas in America (MENAND, 2001). 
realidade - o que Bernstein (2010) descreveu como ansiedade cartesiana. Em suas discussões, Peirce, James e Dewey sentiram a necessidade de reformar, revolucionar e naturalizar conceitos como a razão normativa de Kant e o historicismo de Hegel. Desenvolveram, assim, o pragmatismo como uma filosofia da prática e do engajamento com questões de real importância para as rotinas diárias.

Após A Guerra Civil (1861 - 1865), havia uma atitude inteiramente nova provocada por um grande florescimento das atividades econômicas e a expansão para o oeste. Com esse grande desenvolvimento capitalista e um novo espírito na economia mundial, os norte-americanos não mais se sentiam tão dependentes do pensamento europeu.

O naturalismo dos pragmatistas clássicos norte-americanos, prossegue Bernstein (2010), foi moldado pela ciência do final do século XIX. A contribuição principal veio da teoria darwinista da evolução. A outra forma de explicação científica, que estava chegando à maturidade na época, era a ciência estatística. As explicações evolucionistas e estatísticas diferem dos relatos matemáticos e físicos da realidade, expressos no modelo newtoniano, baseado na necessidade do funcionamento de leis universais infalíveis.

A seleção natural e as estatísticas podem explicar acontecimentos contingentes, apresentando condições sob as quais eles podem ser vistos como pelo menos prováveis. Tais teorias se mostraram mais adequadas para explicar fenômenos sociais, o surgimento do coletivo a partir do individual e os processos através dos quais espécies biológicas surgem e se diversificam. Peirce, James e, sobretudo, Dewey reconheceram que a evolução, em nível das espécies, e a aprendizagem, em nível dos indivíduos, compartilham uma estrutura seletiva comum governada por processos de adaptação nos quais a interação com o ambiente preserva, reproduz e seleciona alguns elementos enquanto outros são eliminados.

\section{PRAGMATISMO E PRAGMATISMO LINGUÍSTICO}

Após Chomsky, tornou-se necessário investigar a possibilidade de que a linguagem seja mais adequadamente vista como um sistema de conhecimento na mente dos seres humanos. Uma 'revolução cognitiva' foi, portanto, necessária para tentar desvendar as relações entre 'linguagem', 'mente' e 'cérebro'. (COBLEY, 2001, p. 5, tradução nossa).

Retomando nossos apontamentos da primeira parte do artigo sobre o problema da falta de caracterização e fundamentação da pragmática como disciplina e a consequente dificuldade em investigar a questão da significação da linguagem, iniciamos, a partir deste ponto, uma exposição de nossas conclusões sobre princípios, temas e conceitos centrais do pragmatismo que podem ser usados para desenvolver uma proposta de pragmatismo linguístico como instrumental teórico para a análise dos usos da linguagem.

Esses instrumentos de análise são construídos com base em conceitos constitutivos do pragmatismo clássico norte-americano como Experiência, Crença, 
Hábitos $^{7}$ e Ação. E esse último conceito - Ação - pode ser interpretado como a própria linguagem.

Em How We Think (1911), Dewey descreve uma ligação muito peculiar e próxima entre linguagem e pensamento. Dewey (1911) lembra que os antigos gregos

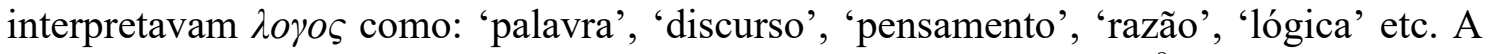
exemplo de Peirce, que afirmava que pensamos através de $\operatorname{signos}^{8}$, Dewey definia a linguagem como ferramenta necessária para o desenvolvimento do pensamento e da comunicação.

Acreditamos que existe uma complexa relação circular entre experiência, crenças, hábitos, pensamento e linguagem. E que a análise dos processos de significação da linguagem deve, portanto, iniciar pelos primeiros, especificamente pelo pragmatismo lógico de Peirce, psicológico de James e instrumental de Dewey.

\section{A TEORIA DOS SIGNOS EM PEIRCE}

Para Peirce, cientista, lógico e filósofo, além das verdades práticas, haveria algum tipo de acordo a longo prazo para descobrir a verdade através dos métodos científicos das comunidades de investigação. Embora, em certo sentido, desmascarasse a velha ideia de verdade absoluta, reverenciada por sistemas filosóficos anteriores, mantinha a visão de que existiria uma verdade, embora essa provavelmente não correspondesse às nossas expectativas.

Em How to Make Our Ideas Clear (1878), Peirce define o conhecimento como fruto de nossa experiência com a realidade, de nossos raciocínios hipotéticos baseados em experiências anteriores e em um processo contínuo de avaliação, aceitação e refutação.

Nossas crenças são realmente regras de ação e, para entender o significado de nossos pensamentos, precisamos apenas determinar quais efeitos serão produzidos na realidade. Esses efeitos são o único significado tangível e a raiz de todas as distinções dos conceitos mentais. (PEIRCE, 1878, p. 8, tradução nossa).

Merrell (2001) descreve o signo peirceano como algo que se relaciona com alguma coisa para alguém em algum aspecto ou capacidade. O signo em Peirce ou 'representamen'9 se divide em três componentes. O representamen é algo que entra em

\footnotetext{
${ }^{7} \mathrm{O}$ conceito pragmático de 'hábitos' vai além das rotinas pessoais e envolve as próprias leis naturais. Pragmáticos substituem Newton por Darwin, necessidade por probabilidade. Assim, leis físicas imutáveis passam a ser encaradas como eventos estatisticamente prováveis.

${ }^{8} \mathrm{O}$ próprio pensamento é, como Platão observou, uma conversa interior ou "um discurso silencioso da alma consigo mesma" (PEIRCE, 1984, p. 172).

${ }^{9}$ Peirce afirma que o homem é um signo e o próprio universo é um vasto representamen ou argumento, exprimindo um logos (platônico) e um telos (aristotélico). O processo de inferência contínua que alimenta a reflexão do homem percorre também toda a natureza. Ocorre que o homem só é capaz de apreender o universo através de operações semióticas e isso alimenta certa 'antropomorfização' ou "o homem como medida de todas as coisas", para citar Protágoras. Mas é necessário ter presente que, quando se fala em signo e no seu modo de funcionamento, esse processo não se refere só, ou exclusivamente, ao homem. Peirce distingue, a propósito, entre signo e representamen (que tem uma acepção mais vasta). Um signo é
} 
relação com seu objeto. O segundo componente do signo é o 'objeto semiótico', pois é aquele ao qual o signo se refere.

O objeto semiótico nunca pode ser idêntico ao objeto 'real', já que, segundo Peirce ${ }^{10}$, nosso conhecimento nunca é absoluto. Portanto, o objeto semioticamente real que sentimos, provamos, tocamos, ouvimos e vemos nunca é idêntico ao objeto 'realmente real', pois nossas mentes são muito limitadas para apreender algo tão sutil e complexo. O terceiro componente do signo é o 'interpretante', próximo do que normalmente descreveríamos como o significado do signo. O interpretante se relaciona e medeia entre o representamen e o objeto semiótico, de modo a provocar uma inter-relação entre eles ao mesmo tempo, e da mesma maneira, que se inter-relaciona com eles.

O signo cria na mente do seu intérprete um interpretante, que Peirce afirma ser um signo equivalente ou até mais desenvolvido. $O$ interpretante possui todas as características de um signo e também se relaciona a um objeto, que produz um novo interpretante: "que sendo também signo, demanda novo interpretante, e assim sucessivamente, ad infinitum" (PEIRCE, 1931-1935, 1958, p. 385). Esse é o esboço do processo que será chamado de semiose ilimitada e que implica na tradução de qualquer pensamento em pensamentos subsequentes, formando uma cadeia de pensamentos e "tecendo a trama dos signos" (SANTAELLA, 1994, p. 101).

Merrell (2001) apresenta as classes mais básicas do signo peirceano como 'ícones, índices e símbolos'. Um 'ícone' é um signo que se inter-relaciona com seu objeto semiótico em virtude de alguma semelhança entre eles, como um mapa e o território mapeado. Um 'índice' é um signo que se inter-relaciona com seu objeto semiótico através de alguma conexão causal real, física ou imaginária, como um catavento indicando a direção do vento. Símbolos são mais complexos, uma vez que sua inter-relação com o objeto semiótico é convencional e arbitrária, algo parecido com o signo linguístico de Saussure.

Merrell (2001) conclui com uma oportuna explicação dos processos de formação (semiose) e significação (semiótica) do signo peirceano, por meio de suas três categorias: 'primeiridade, secundidade e terceiridade'. 'Primeiridade' é possibilidade ou qualidade (o que pode ser), 'secundidade' é atualidade ou relação (o que acontece no momento) e 'terceiridade' é potencialidade ou representação (o que poderia ser, dado um certo conjunto de condições).

Na pintura (MERRELL, 2001), primeiridade poderia ser uma mancha colorida, retangular bidimensional em uma tela de Picasso. Secundidade seria a inter-relação interativa desse traço com outros pontos retangulares e triangulares na tela. Terceiridade seria o olhar do espectador que reúne esses pontos em uma imagem imaginária tridimensional como se vista de frente, de trás, do lado direito, do lado esquerdo, de cima e de baixo, tudo em simultaneidade.

um representamen com um interpretante mental (quasi-mind), isto é, signo é um representamen para o homem; mas há formas de signos (representamens) ativas na natureza, realizando processos semióticos, mesmo que o seu destinatário não seja o homem. (Os autores)

${ }^{10} \mathrm{Cf}$. Antifundacionismo e falibilismo (BERNSTEIN, 2010) 
Na poesia, propõe Merrel (2001), primeiridade seriam algumas linhas como marcas no papel e sua possibilidade de serem lidas em algum lugar, em algum momento por algum amante da poesia. Secundidade seria a leitura real e sua inter-relação com a poesia como literatura. Terceiridade seria a interação e a interpretação do leitor sobre o referido texto poético.

Para Cobley (2001), a semiótica de Peirce precede e é muito mais abrangente do que a semiologia de Saussure, que se ocupou basicamente do signo linguístico nas línguas naturais. Entretanto, o fenômeno da linguagem humana constitui apenas um aspecto da semiose, a teoria geral dos signos em todo o universo. A comunicação também é uma forma de semiose voltada para a troca de mensagens entre quaisquer tipos de sistemas (inter) dependentes: do código molecular e das propriedades imunológicas da célula até as mensagens vocais. $\mathrm{O}$ alcance da semiótica de Peirce permite o estudo da significação das mensagens em qualquer interação que envolva o uso de signos.

\section{O CONCEITO DE CASH VALUE EM JAMES}

Em The Will to Believe (1896), James discute os pilares de sustentação do pragmatismo clássico norte-americano presentes nos conceitos de 'experiência', 'hábito', 'ação' e 'crença'. Seu conceito de cash value se baseia na psicologia, formação, necessidade e o papel das crenças nos processos de significação do pensamento e da linguagem e também explica sua abordagem particular de verdade como um sistema de crédito.

James (1896) argumenta contra o evidencialismo científico em favor da alegação de que, sob certas condições, nossa natureza passional pode determinar crenças individuais mesmo na ausência de provas. A exemplo do que ocorre com a eletricidade, hipóteses podem ter ou não 'corrente'. Uma hipótese carregada apela como possibilidade real. Já uma proposta sem carga deixa de provocar efeitos porque não consegue 'empolgar' e isso comprova que a repercussão de uma hipótese não é uma propriedade intrínseca, mas varia em relação a cada indivíduo.

Para James (1896), as opções podem ser de vários tipos: (i) com ou sem carga; (ii) forçadas ou evitáveis; e (iii) significativas ou triviais. Uma opção é genuína quando for do tipo 'com carga', 'forçada' e 'significativa', segundo nossas convicções e segundo aquilo em que se é útil e conveniente acreditar.

James (1896) defende que nossa natureza passional não apenas pode, mas também deve decidir por uma opção entre proposições, sempre que essa opção for genuína e que não possa, por sua natureza, ser decidida em bases intelectuais. Não decidir e deixar a questão em aberto é em si uma decisão passional - assim como decidir por sim ou por não - e todas correm o mesmo risco de não corresponder à verdade.

The Will to Believe (1886) revela o pioneirismo e a coragem de James em tratar de questões polêmicas como o papel da fé e os efeitos da experiência religiosa no comportamento humano. James (1886) trata a crença em Deus como uma questão em aberto, algo que não é possível resolver racionalmente e, portanto, perfeitamente justificáveis por meios não racionais. Menções religiosas provocam determinadas reações 
entre seguidores de diferentes sistemas de fé e, por certo, soariam ainda mais diferentes ou indiferentes para ouvidos ateus.

James (1886) oferece três argumentos para apoiar sua tese. Em primeiro lugar, estamos lidando com uma questão aberta e sem solução. Segundo, a questão requer uma posição e você é de alguma forma forçado a colocar em cheque suas crenças ou descrenças. Você não pode simplesmente dar de ombros, porque ignorar a questão já define um tipo de escolha e postura. Terceiro, se trata de uma decisão importante porque realmente afeta a maneira como você vive, revela seu temperamento e expressa seus valores. James (1886) conclui que tal vontade ou necessidade de acreditar em alguma coisa faz parte da nossa natureza, mas, ao mesmo tempo, nos obriga a escolher uma posição, a assumir compromissos e aceitar suas consequências.

Se, por um lado, a semiótica peirceana é de suma importância para uma fundamentação lógica de um pragmatismo linguístico, por outro lado, as contribuições de James, médico e psicólogo, com seus trabalhos pioneiros sobre a filosofia da mente, são igualmente importantes porque permitem um estudo mais detalhado das ligações lógicas e emocionais entre pensamento e linguagem, experiência e crença.

Em The Principles of Psychology (1890), James antecipa discussões sobre as relações entre darwinismo e a psicologia experimental. $O$ homem, segundo sua concepção, é um organismo físico, inserido em um ambiente natural e sua sobrevivência e evolução dependem de suas estratégias mentais, hábitos, discurso e ações.

A verdade é que as amplas sucessões de discurso humano não são nada além de sinais de direção no pensamento, de cuja direção nós temos um sentido agudamente discriminativo, não obstante, nenhuma imagem sensorial definida desempenhe qualquer papel nele. As imagens sensoriais são fatos psíquicos estáveis; podemos mantê-las quietas e observá-las, tanto quanto queiramos. Essas imagens vazias do movimento lógico, ao contrário, são transações psíquicas, por assim dizer, sempre em voo e que não podem ser vislumbradas a não ser no voo. (JAMES, 1890, p. 252-253, tradução nossa).

Goodman (2002) aponta para um longo envolvimento de Wittgenstein com o pragmatismo de James. Segundo o autor, James exerceu uma clara e penetrante influência no pensamento de Wittgenstein. Os dois filósofos destacaram a importância da experiência humana concreta e a prioridade da prática sobre o intelecto nos processos de significação da linguagem.

Pihlström (2011) também defende que determinadas concepções da filosofia da linguagem em James e Wittgenstein estabelecem ligações promissoras entre pragmatismo e filosofia pós-analítica. De fato, Pihlström (2011) não tem problemas em afirmar que Wittgenstein ocupa um lugar na interseção entre o pragmatismo e a filosofia transcendental kantiana, de tal maneira que essas duas tradições se encontram no seu pensamento posterior - especialmente e postumamente em On Certainty (1969), cuja abordagem básica tem sido descrita como uma forma de pragmatismo por alguns neopragmáticos como Rorty e Putnam. 
Pihlström (2011) se dispõe a admitir que o segundo Wittgenstein é tanto um pragmático - afinal, seus jogos de linguagem são formas práticas de 'estar no mundo', baseados em práticas ou 'formas de vida' - quanto um pensador transcendental kantiano envolvido com a questão da possibilidade do significado.

Historicamente, James exerceu um papel fundamental por ser o grande divulgador do pensamento lógico de Peirce. Mas, ao mesmo tempo, James desenvolveu sua própria versão de pragmatismo baseado na psicologia social. Por sua vez, seu naturalismo pragmático teve um grande impacto na formação das teorias do conhecimento e da investigação no pragmatismo instrumental de Dewey.

\section{O CONCEITO DE WARRANTED ASSERTIBILITY EM DEWEY}

A exemplo de James, Dewey, filósofo de formação e educador, é menos reformista e mais revolucionário em seu pensamento. Dewey também define a verdade como aquilo em que se é útil acreditar. Entretanto, segundo seu conceito de warranted assertibility (discursos justificáveis), tais verdades dependem de reflexão. Antes de afirmar algo, você tem que ter razão suficiente para apresentar suas declarações como verdadeiras e como resultado de conhecimentos decorrentes de processos de investigação competentes.

Em Logic - The Theory of Inquiry (1939), Dewey defende que processos de investigação, se devidamente lógicos e científicos, trazem legitimidade aos discursos e que as ideias se tornam verdadeiras quando funcionam, cumprem sua finalidade e encontram soluções para os problemas para os quais foram criadas.

Segundo Johnson (2010), com sua visão de mente, pensamento e linguagem, Dewey antecipou em mais de oitenta anos o que viriam a ser os objetos de estudo das ciências cognitivas. Dewey desenvolveu suas teorias, a partir de pesquisas empíricas, nos campos de várias ciências como o da biologia, das neurociências, da antropologia, da psicologia cognitiva, da psicologia desenvolvimentista e da linguística. O conceito de 'experiência', central no pensamento de Dewey, deve incluir todos os acontecimentos que envolvem as interações complexas e contínuas entre organismos e seus meios.
A noção de experiência envolve todas as ações e reações dos seres humanos, suas lutas, paixões, crenças e resistências, e também como agem e as consequências de seus atos, o modo como sofrem, desejam, aproveitam, veem, acreditam e imaginam a vida - resumindo, os processos da experiência. (DEWEY,1929, p. 42, tradução nossa)

Essa visão funcional da mente em Dewey envolve dimensões biológicas, mas é também fundamentalmente um fenômeno social. Funções cognitivas superiores, como a conceptualização, a razão e a linguagem, emergem a partir de funções inferiores relacionadas à percepção, às habilidades motoras e às emoções. Dewey defende um naturalismo não metafísico baseado no princípio da continuidade: "não há quebra de continuidade entre as funções cognitivas, biológicas e físicas. 'Continuidade' significa que a razão nasce de atividades orgânicas, sem ser idêntica àquilo que lhe deu origem". (DEWEY, 1939, p. 19). 
Quanto à questão da significação na linguagem, para Dewey, a palavra ou símbolo adquire significado dentro das comunidades humanas à medida que esses símbolos conseguem apontar para possíveis experiências passadas, presentes ou futuras: "os significados regem o uso e a interpretação das ideias; a interpretação é sempre uma imputação da potencialidade de alguma consequência" (DEWEY, 1929, p. 222).

Johnson (2010) aponta que alguns dos mais importantes fundamentos da teoria dos atos de fala já estão presentes no pensamento de Dewey:

O coração da língua não está na 'expressão de algo anterior', muito menos na expressão de pensamentos prévios. Ele está na comunicação; no estabelecimento de uma atividade de cooperação entre parceiros, na qual a atividade de cada um é modificada e regulada por tal parceria. Os símbolos adquirem significado através de seu uso funcional para informar, questionar, implorar, planejar, expressar senso de humor, além de outras formas de interações humanas. (DEWEY, 1929, p. 213, tradução e grifo nossos).

Para Dewey, a mente é produto das interações simbólicas e do compartilhamento de significados dentro de comunidades linguísticas. A mente representa o horizonte de significados potencialmente compartilháveis entre seres dotados de linguagem, enquanto que a consciência individual é a percepção real de um organismo específico de significados específicos conforme suas crenças e experiência.

\section{CONSIDERAÇÕES FINAIS}

Iniciamos o presente artigo com uma descrição dos problemas enfrentados pela disciplina pragmática, segundo as avaliações de renomados pesquisadores da área e definimos como nosso objetivo principal buscar um número suficiente de conceitos e princípios para caracterizar e fundamentar, de "forma mais técnica" (MARCUSCHI, 1996, p. 21-22), uma proposta de pragmatismo linguístico para investigar a questão "do uso concreto da linguagem feito pelos seus usuários e as condições que governam essa prática" (HABERLAND; MEY, 1977, p. 1).

Os dois primeiros caminhos indicados por Pinto (2012), envolvendo os trabalhos de William James e J. L. Austin, revelam significantes convergências entre as Viradas Pragmática e Linguística. Tanto Peirce, James e Dewey quanto Wittgenstein, Austin e Ryle perceberam que as discussões filosóficas não podem ir além dos limites da linguagem. Ao se debruçarem sobre temas afins e buscarem respostas nas mesmas fontes, esses autores chegaram a conclusões semelhantes. Entretanto, é necessário dizer que, historicamente, a Virada Pragmática precede a Virada Linguística e isso nos fez enveredar por esse caminho ${ }^{11}$.

\footnotetext{
${ }^{11}$ Misak (2014) defende que a Virada Linguistica de Wittengenstein foi antecipada pela Virada Pragmática de Peirce em Cambridge, 'Massachussetts'. Misak (2014) afirma que Frank Ramsey, jovem filósofo britânico, inspirado pelo pensamento de Peirce sobre as relações entre crenças, hábitos e ação, acabou por influenciar seu colega Wittgenstein. Misak (2014) relata que Ramsay compreendeu as ideias de Peirce como poucos e passou a desenvolvê-las e divulgá-las. Assim, as discussões profundas iniciadas no Methaphysical Club acabaram encontrando eco nos encontros dos não menos ilustres membros do Cambridge Apostles.
} 
Como resultado da nossa pesquisa, apresentamos um breve relato das origens do pragmatismo norte-americano. Segundo Stout (2012), Peirce inventou o pragmatismo, James uniu o mundo da experiência humana e o da linguagem e Dewey transformou o pragmatismo em um instrumento de progresso social, cultural e de conscientização democrática. Santaella (1994) identifica no trabalho de Peirce uma "exposição e absorção de 25 séculos de tradição filosófica ocidental porque representadas através de uma configuração inalienável entre linguagem e pensamento" (1994, p. 82). James e Dewey aprofundam com brilho essas análises e discussões.

As preocupações do pragmatismo norte-americano com as questões da linguagem, como dissemos anteriormente, são históricas. Quanto às suas contribuições para a construção de uma proposta de pragmatismo linguístico, podemos dizer que a busca da verdade está para os sistemas filosóficos assim como a busca da significação está para a linguagem. Encontramos no pensamento dos pragmáticos clássicos norte-americanos uma discussão relevante sobre a essência e o caráter da mente na coordenação da experiência, sobre a criação dos sistemas de conhecimento e sobre o estabelecimento de crenças, hábitos e ações que se traduzem na linguagem.

Ressaltamos que a doutrina dos signos de Peirce é interdisciplinar por natureza porque ultrapassa os limites do signo linguístico sassureano. O interesse principal de Peirce sempre foi o de desenvolver um método lógico-científico que tornasse possível uma representação mais verdadeira da realidade. Por esse motivo, sua teoria semiótica é muito mais abrangente do que a semiologia localizada de Saussure.

Sebeok (2001), por exemplo, questiona se a semiose faz parte da linguística ou se deveria ser o contrário já que a comunicação não acontece apenas entre seres sencientes (inteligentes), mas também envolve organismos unicelulares, multicelulares, anfíbios, mamíferos, etc. $\mathrm{O}$ autor lembra também que os complexos processos de comunicação vão muito além dos sinais vocais e podem envolver ainda meios acústicos, químicos, elétricos, térmicos, ópticos, etc.

A categoriologia peirceana, que vai muito além do que foi possível apresentar neste ensaio, envolve uma intricada urdidura construída com base em complexas interrelações entre categorias (primeiridade, secundidade e terceiridade); classes (representamen, objeto e interpretante) e subclasses de signos. Dessa forma, os sistemas lógicos desenvolvidos por Peirce podem ser empregados na análise dos processos de formação (semiose) e significação (semiótica) dos signos no pensamento e na linguagem.

Quanto a James, seus trabalhos sobre filosofia da mente e percepção permitem estudos das ligações entre linguagem e pensamento. A relevância do seu conceito de cash value está no seu poder explicativo sobre a formação de um tipo muito comum de crenças pessoais ou subjetivas. Seu conceito também permite analisar as influências e o papel das nossas crenças nos processos de significação da linguagem.

Por último, algumas considerações sobre o pensamento de Dewey, o mais longevo, produtivo e mais próximo do nosso tempo entre os três pragmáticos clássicos norte-americanos. Herdeiro de Peirce e James, Dewey desenvolveu e refinou seus 
próprios conceitos lógicos, éticos e estéticos e construiu uma teoria de investigação sobre a relação orgânica entre indivíduos e seus ambientes físicos, culturais e sociais. Dewey definiu essa relação como 'experiência' e concluiu que essa só se torna possível através da comunicação humana: "o mais intrigante dos fenômenos" (HICKMAN, 2004, p. 162).

Dewey desenvolve sua versão do conceito de 'comunidade de investigação', um dos temas característicos do pragmatismo, quando afirma que os processos inferenciais de investigação iniciam a partir de um problema, de ordem natural ou social, que passa a ser analisado conforme métodos apoiados na ciência.

Nas ciências naturais, as investigações começam pelos fenômenos naturais enquanto que, nas ciências sociais, as investigações iniciam pela questão do que 'deve' ser feito. E aí está o mais importante aspecto ético no trabalho de Dewey. As investigações têm como objetivo dar ao indivíduo condições razoáveis de emitir pareceres, fazer julgamentos ou declarações sobre uma dada situação. Warranted assertibility são discursos justificáveis, salvo melhor juízo, sobre estados da realidade, legítimos até que surjam novas informações ou fatos e novos processos de investigação tenham que ser iniciados.

Finalmente, destacamos a centralidade do conceito de 'experiência' no pensamento dos três pragmáticos clássicos norte-americanos. Defendemos a tese de que essa experiência, ou interação entre seres vivos e seus ambientes, age na formação de nossas crenças, que estão por trás dos processos de significação da linguagem. A semiótica de Peirce permite análises do papel dos signos na constituição das diferentes formas de comunicação. O conceito de cash value em James pode ser usado no estudo das crenças mais subjetivas. Já o conceito de warranted assertibility ou discursos justificáveis em Dewey permite a análise da formação social e da legitimidade do discurso.

Assim, estudos dos fundamentos e princípios do pragmatismo lógico em Peirce, psicológico em James e instrumental em Dewey tornam possíveis vários tipos de análise dos processos de significação nos usos da linguagem.

\section{REFERÊNCIAS}

BERNSTEIN, John Richard. The Pragmatic Turn. 65 Bridge Street, Cambridge CB2 1UR, UK: Polity Press, 2010.

CHOMSKY, Noam. Noam Chomsky on the hard stuff. Em: The Philosopher's Zone ABC Radio. Disponível em

$<$ http://www.abc.net.au/radionational/programs/philosopherszone/noam>; acesso em 17 maio 2017.

COBLEY, Paul. Introduction. Part I Semiosis, communication and language. Em: The Routledge Companion to Semiotics and Linguistics. 11 New Fetter Lane, London EC4P 4EE: Routledge, 2001. p. 03-13.

COCHRAN, Molly. Introduction. Em: The Cambridge Companion to Dewey. New York: Cambridge University Press, 2010. p. 01-13.

DEWEY, John. Experience and Nature. Ruskin House, 40 Museum Street, W.CX, London: George Allen \& Unwin Ltd, 1929. 
DEWEY, John. How We Think. The Project Gutenberg EBook. September 14, 2011. [EBook \#37423]. Disponível em $<$ http://www.pgdp.net.>; acesso em 17 jun. 2018.

DEWEY, John. Logic, the Theory of Inquiry. New York: Henry Holt and Company Inc., 1939.

GOODMAN, Russell B. Wittgenstein and William James. The Edinburgh Building, Cambridge CB2 2RU, UK: Cambridge University Press, 2002.

HABERLAND, Harmut; MEY, Jacob. Editorial: Linguistics and pragmatics. Em: JOURNAL OF PRAGMATICS. Volume 1, Issue 1. April 1977. p. 1-12.

HICKMAN, Larry, A. John Dewey, 1859-1952. Em: The Blackwell Guide to American Philosophy. MARSOOBIAN, Armen, T; RYDER, John (Editors). Oxford: Blackwell Publishing, 2004. p. 155-173.

JAMES, William. American Science Series - Advanced Course. The Principles of Psychology. New York: Henry Holt and Company, 1890.

JAMES, William. The Will to Believe. An Address to the Philosophical Clubs of Yale and Brown Universities. June, 1896. Disponível em $<$ https://www.mnsu.edu $>$; acesso em 05 out. 2018.

JAMES, William. Pragmatism - A New Name for Some Old Ways of Thinking. 1907. Disponível em

$<$ https://ebooks.adelaide.edu.au/j/james/william/pragmatism/complete.html. $>$; acesso em 01 fev. 2018.

JOHNSON, Mark. 6 Cognitive Science and Dewey's Theory of Mind, Thought, and Language. Em: The Cambridge Companion to Dewey. COCHRAN, Molly (Editor). Georgia Institute of Technology. New York: Cambridge University Press, 2010. p. 123144.

MARCUSCHI, Luiz Antônio. 48 ${ }^{\text {a }}$ REUNIÃO ANUAL DA SBPC. 7 a 12 de julho de 1996. PUC/SP. 1996, p. 21-22.

Disponível em $<$ http://portal.sbpcnet.org.br/eventos/48ra/>; acesso em $01 \mathrm{dez} .2017$.

MERRELL, Floyd. 2 Charles Sanders Peirce's Concept of the Sign. COBLEY, Paul (Editor). Em: The Routledge Companion to Semiotics and Linguistics. 11 New Fetter Lane, London EC4P 4EE: Routledge, 2001. p. 28-39.

PEIRCE, Charles Sanders. How to Make Our Ideas Clear. Em: POPULAR SCIENCE MONTHLY 12. New York, USA. 1878. p. 286-302.

PEIRCE, Charles Sanders. The Collected Papers of Charles Sanders Peirce. A Disordered Array of Severed Limbs. Vols. I-VIII. DEELY, John; HARTSHORNE, Charles; WEISS, Paul. Cambridge, MA: Harvard University Press, 1931-1935, 1958. Disponível em $<$ https://docero.com.br/doc/s1xnce $>$; acesso 14 jan. 2020.

PEIRCE, Charles Sanders. Writings of Charles S. Peirce: A Chronological Edition, Volume 2. (1867-71). Bloomington, IN: Indiana University Press, 1984.

PEIRCE, Charles Sanders. The Essential Peirce: Selected Philosophical Writings, Vol. 1: 1867-1893. HOUSER, Nathan; KLOESEL, Christian (Editors). Bloomington, IN: Indiana University Press, 1992.

PEIRCE, Charles Sanders. Reasoning and the Logic of Things. Cambridge, MA: Harvard University Press, $1992 \mathrm{~b}$.

PIHLSTRÖM, Sami. 3 Research Methods and Problems. Em: The Continuum Companion to Pragmatism. PIHLSTRÖM, Sami (Org.). New York: Continuum International Publishing Group, 2011. p. 46-69.

PINTO, Joana Paza. Pragmática. Em: Introdução à Linguística, Domínios e Fronteiras. Volume 2, $8^{\text {a }}$ Edição. MUSSALIM, Fernanda; BENTES, Anna Christina (Orgs.). São Paulo: Editora Cortez, 2012. p. 47-68. 
RAJAGOPALAN, Kanavillil. Os Caminhos da Pragmática no Brasil. (Pragmatic Studies in Brazil). D.E.L.T.A., Vol. 15, N. ${ }^{\circ}$ Especial. Unicamp. 1999. p. 323-338. Disponível em $<$ http://www.scielo.br/pdf/delta/v15nspe/4021.pdf>; acesso em 01 dez. 2017.

SANTAELLA, Lúcia. O que é semiótica. 11. ed. São Paulo: Coleção Primeiros Passos - 103. Brasiliense, 1994.

SEBEOK, Thomas Albert. 1 Nonverbal Communication. COBLEY, Paul (Editor). Em: The Routledge Companion to Semiotics and Linguistics. 11 New Fetter Lane, London EC4P 4EE: Routledge, 2001. p. 14-27.

STOUT, Jeffrey. The Spirit of Pragmatism. Bernstein's Variations on Hegelian Themes. Em: FACULTY PHILOSOPHY JOURNAL. Volume 33, Number 1. 2012. p. 185246.

Artigo recebido em: set. de 2019.

Aprovado e revisado em: mar. de 2020.

Publicado em: julho de 2020.

Para citar este texto:

SILVA, Jorge Francisco da.; EFKEN, Karl Keinz. Pragmatismo e Linguagem: fundamentos de um pragmatismo linguístico segundo o pensamento de Peirce, James e Dewey. Entremeios [Revista de Estudos do Discurso, ISSN 2179-3514, on-line, www.entremeios.inf.br], Seção Estudos, Programa de Pós-Graduação em Ciências da Linguagem (PPGCL), Universidade do Vale do Sapucaí (UNIVÁS), Pouso Alegre (MG), vol. 21, p. 38-52, jan. - jun. 2020.

DOI: http://dx.doi.org/10.20337/ISSN2179-3514revistaENTREMEIOSvol21pagina38a52 